\title{
Faktor-faktor yang mempengaruhi fertilitas di Kampung Keluarga Berencana (KB) di Kecamatan Muara Bulian Kabupaten Batanghari
}

\author{
Novi Prayanti*; Zulfanetti; Junaidi; Ira Wahyuni \\ Prodi Magister Ilmu Kependudukan dan Ketenagakerjaan, Universitas Jambi \\ E-mail korespodensi : noviprayanti745@gmail.com
}

\begin{abstract}
The purpose of this study was to determine the profile of the Family Planning Village in Muara Bulian District, Batanghari Regency, to determine the characteristics of EFA in the Family Planning Village in Muara Bulian District, Batanghari Regency, to analyze the influence of the level of age at first marriage, family income, education, employment status. in Muara Bulian District, Batanghari Regency. The analytical tool used descriptive analysis to analyze data by describing or describing the data and multiple regression analysis. The results of the analysis of this study are that the results of the research that have been carried out on the factors that influence fertility in the Family Planning Village of Batanghari Regency, it is found that the Age of First Marriage, women who have a fertility opportunity of more than 2 have an essential effect in increasing the birth rate. Income, women with a fertility opportunity of more than 2 have an important influence in improving fertility. Junior high school education, in this study, women who have low education do not affect the opportunity to increase fertility. SLTA + education, in this study, women who have higher education do not affect increasing fertility. Employment status, in this study, women who work do not affect increasing fertility.
\end{abstract}

Keywords: Age of first marriage, Income, Education, Employment status on fertility.

\section{Abstrak}

Tujuan penelitian ini adalah untuk mengetahui Profil di Kampung Keluarga Bencana di Kecamatan Muara Bulian Kabupaten Batanghari, untuk mengetahui karakteristik PUS yang ada di Kampung Keluarga Berencana di Kecamatan Muara Bulian Kabupaten Batanghari, untuk menganalisis pengaruh tingkat usia kawin pertama, pendapatan keluarga, pendidikan, status pekerjaan di Kecamatan Muara Bulian Kabupaten Batanghari. Alat analisis yang digunakan analisis deskriptif untuk menganalisis data dengan mendeskripsikan atau menggambarkan data dan analisis regresi berganda. Hasil analisis penelitian ini adalah bahwa hasil analisis yang telah dilakukan terhadap Faktorfaktor Yang Mempengaruhi Fertilitas di Kampung Keluarga Berencana Kabupaten Batanghari ditemukan bahwa Usia Kawin Pertama, wanita yang mempunyai peluang fertilitas lebih dari 2 mempunyai pengaruh penting dalam meningkatkan angka kelahiran. Pendapatan, wanita yang mempunyai peluang fertilitas lebih dari 2 mempunyai pengaruh penting dalam meningkatkan fertilitas. Pendidikan SLTP, pada penelitian ini wanita yang mempunya pendidikan rendah tidak mempunyai pengaruh terhadap peluang meingkatkan fertilitas. Pendidikan SLTA+, pada penelitian ini wanita yang mempunya pendidikan tinggi tidak mempunyai pengaruh terhadap peningkatan fertilitas. Status Pekerjaan, pada penelitian ini wanita yang bekerja tidak mempunyai pengaruh terhadap peningkatan fertilitas.

Kata kunci : Usia kawin pertama, Pendapatan, Pendidikan, Status Pekerjaan pada fertilitas 
Jurnal Paradigma Ekonomika Vol.16. No.3, Juli - September 2021 ISSN: 2085-1960 (print); 2684 -7868 (online)

\section{PENDAHULUAN}

Aspek kependudukan merupakan hal paling mendasar dalam pembangunan. Dalam nilai universal, penduduk merupakan pelaku dan sasaran pembangunan sekaligus yang menikmati hasil pembangunan. Dalam kaitan peran penduduk tersebut, kualitas mereka perlu ditingkatkan melalui berbagai sumber daya yang melekat, dan pewujudan keluarga kecil yang berkualitas, serta upaya untuk menskenario kuantitas penduduk dan persebaran kependudukan. Jumlah penduduk, komposisi umur, dan lajupertambahan atau penurunan penduduk dipengaruhi oleh fertilitas (kelahiran), mortalitas (kematian), dan migrasi (perpindahan tempat) karena ketiga variabel tersebut merupakan komponen-komponen yang berpengaruh terhadap perubahan penduduk (Lucas, 1990).

Menurut Mantra dalam Rakhmatullah (2015) pengendalian fertilitas merupakan salah satu cara untuk mengendalikan jumlah penduduk. terdapat sejumlah faktor yang dapat mempengaruhi tingkat fertilitas yaitu, (1) faktor demografi yang terdiri dari : komposisi umur, status perkawinan, umur kawin pertama, fekuditas, proporsi penduduk yang bersatatus kawin, dan (2) Faktor non demografi diantaranya ekonomi penduduk, tingkat pendidikan, perbaikan status wanita, urbanisasi dan industrialisasi. Faktor-faktor tersebut dapat berpengaruh langsung ataupun tidak langsung terhadap fertilitas. Selain itu faktor sosial juga dapat mempengaruhi tingkat pendidikan ibu, statusketenagakerjaan ibu, usia kawin pertama ibu, penggunaan alat kontrasepsi dan tingkat pendapatan orang tua.

Di dalam upaya pencapaian 6 (enam) Sasaran Strategis diatas, BKKBN harus dapat melakukan berbagai langkah penguatan program Kependudukan, KB dan Pembangunan Keluarga (KKBPK) yang benar-benar memiliki daya ungkit terhadap upaya pencapaian target/sasaran, serta penguatan kegiatan-kegiatan prioritas secara komprehensif dan berkelanjutan di seluruh tingkatan wilayah. Selain itu, BKKBN juga harus memperhatikan perkembangan lingkungan strategis dan berbagai permasalahan program yang harus dihadapi saat ini. Beberapa permasalahan yang perlu mendapat perhatian khusus antara lain stagnasi pencapaian program dan semakin melemahnya implementasi Program KKBPK di lini lapangan. Berdasarkan hasil evaluasi internal yang dilakukan dan atas petunjuk Bapak Presiden RI, maka kemudian dirumuskan beberapa inovasi strategis penguatan Program KKBPK untuk periode 2015-2019 terutama untuk melaksanakan kegiatan prioritas yang memiliki daya ungkit terhadap upaya pencapaian target/sasaran yang telah ditetapkan serta memperluas cakupan penggarapan Program KKBPK di seluruh tingkatan wilayah.

Dan jumlah penduduk Provinsi Jambi pada tahun 2015 sebesar 3.402,1 dengan TFR 2,31 kemudian di tahun 2020 menjadi sebesar 3.624,5 dengan TFR 2,18 jadi TFR Provinsi Jambi menurun dinilai cukup baik walaupun jumlah penduduk melampaui angka 3 juta jiwa ( Sumber : BPS Provinsi Jambi Tahun 2020). Angka laju pertumbuhan penduduk Kabupaten Batanghari menurut data Badan Pusat Statistik 2015 dengan TFR 2,12 dengan jumlah penduduk sebesar 275.504 jiwa pada tahun 2020, dari data kependudukan tersebut diatas dinilai sudah cukup baik walaupun jumlah penduduk kota ini sudah melampaui angka 2 ratus jiwa. Apabila pertumbuhan penduduk tidak terkndali dan tidak di tangani pada masa mendatang akan menjadi salah satu kendala dalam pembangunan di beberapa sektor.

Partisipasi aktif masyarakat dalam pengelolaan dan pelaksanaan seluruh kegiatan yang akan dilakukan di Kampung KB secara berkesinambungan guna meningkatkan taraf hidup seluruh masyarakat yang di wilayahnya. Berikut daftar Kampung KB d Kabupaten Batanghari, Di Kampung KB Kabupaten Batanghari terdapat 8 kecamatan dan 22 desa yang diplih menjadi lokasi tempat Kampung KB terdiri dari desa rantau gedang dan desa sengkati kecil yang ada di Kecamatan Mersam, desa rantau kapas tuo dan dan desa pulau yang ada di Kecamatan Muara Tembesi, desa sungai baung dan desa napal sisik yang ada di Kecamatan Muara Bulian, desa olak besar desa jangga dan desa koto boyo yang ada di 
Kecamatan Batin XXIV, desa kuap dan desa olak rambahan yang ada d Kecamatan Pemayung, desa tebing tinggi desa sungai lingkar desa sungai ruan ulu da desa mekar sari yang ada di Kecamatan Maro Sebo Ulu, desa bungku desa ladang peris desa penerokan desa petajen yang ada di Kecamaan Bajubang, kelurahan terusan desa terusan dan desa danau embat yang ada di kecamatan maro sebo ilir. Dengan jumlah PUS yang ada diKampung KB dari tahun 2015-2020 di Batanghari sejumlah 48.841, terdiri dari 8 Kecamatan. Dan kecamatan tersebut adalah Kecamatan Muara Bulian sebanyak 10.079 PUS, Kecamatan Mersam sebesar 5.388 PUS, Kecamatan Muara tembesi sebanyak 5.752 PUS, Kecamatan Batin XXIV sebanyak 5.194 PUS, Kecamatan Pemayung sebanyak 6.044 PUS, Kecamatan Maro Sebo Ulu sebanyak 6.240 PUS, Kecamatan Bajubang sebanyak 7.474 PUS dan sedangkan Kecamatan Maro Sebo Ilir sebanyak 2.670 PUS. Dan jumlah seluruh PUS di Kabupaten Batanghari yang ada di Kampung KB adalah sejumlah 48.841 PUS. Dilihat dari banyaknya PUS di setiap Kecamatan, Kecamatan Muara Bulian Lebih banyak PUS dibandingkan dengan kecamatan lainnya, dengan jumlah PUS Kecamatan Muara Bulian sebanyak 10.079 PUS. ( Sumber : BKKBN Kabupaten Batanghari ).

Tujuan penelitian untuk mendeskripsikan Profil di Kampung KB di Kecamatan Muara Bulian Kabupaten Batanghari, untuk mendekripsikan tingkat fertilitas di Kampung KB di Kecamatan Muara Bulian Kabupaten Batanghari, untuk menganalisis pengaruh tingkat usia kawin pertama, pendapatan keluarga, pendidikan, status pekerjaan terhadap fertilitas di Kecamatan Muara Bulian Kabupaten Batanghari.

\section{TINJAUAN PUSTAKA}

\section{Fetilitas}

Fertilitas sebagai istilah demografi diartikan sebagai hasil reproduksi yang nyata dari seorang wanita atau kelompok wanita. Dengan kata lain fertilitas ini menyangkut banyaknya bayi yang lahir hidup. Fertilitas mencakup peranan kelahiran pada perubahan penduduk. Istilah fertilitas adalah sama dengan kelahiran hidup (live birth), yaitu terlepasnya bayi dari rahim seorang perempuan dengan ada tanda-tanda kehidupan; misalnya berteriak, bernafas, jantung berdenyut, dan sebagainya (Mantra, 2003).

\section{Konsep fertilitas}

Lahir hidup (Life Birth), menurut WHO, adalah suatu kelahiran seorang bayi tanpa memperhitungkan lamanya di dalam kandungan, dimana si bayi menunjukkan tandatanda kehidupan, misal : bernafas, ada denyut jantungnya atau tali pusat atau gerakangerakan otot, Lahir mati (Still Birth) adalah kelahiran seorang bayi dari kandungan yang berumur paling sedikit 28 minggu, tanpa menunjukkan tanda-tanda kehidupan, Abortus adalah kematian bayi dalam kandungan dengan umur kurang dari 28 minggu. Ada dua macam abortus : disengaja (induced) dan tidak disengaja (spontaneus). Abortus yang disengaja mungkin lebih sering kita kenal dengan istilah aborsi dan yang tidak disengaja lebih sering kita kenal dengan istilah keguguran, Masa reproduksi (Childbearing age) adalah masa dimana perempuan melahirkan, yang disebut juga usia subur (15-49 tahun).

\section{Indikator fertilitas}

Pengukuran fertilitas lebih kompleks dibandingkan dengan pengukuran mortalitas, karena seorang perempuan hanya meninggal satu kali, tetapi ia dapat melahirkan lebih dari seorang bayi. Disamping itu seorang yang meninggal pada hari dan waktu tertentu, berarti mulai saat itu orang tersebut tidak mempunyai resiko kematian lagi Sebaliknya 
seorang perempuan yang telah melahirkan seorang anak tidak berarti resiko melahirkan dari perempuan tersebut menurun (Mantra, 2003).

\section{Pengertian Kampung KB}

Pengertian Kampung KB adalah satuan wilayah setingkat RW, dusun atau setara, yang memiliki kriteria tertentu, dimana terdapat keterpaduan program kependudukan, keluarga berencana, pembangunan keluarga dan pembangunan sektor terkait yang dilaksanakan secara sistemik dan sistematis. Kampung KB direncanakan, dilaksanakan dan dievaluasi oleh dan untuk masyarakat. Pemerintah, Pemerintah daerah, lembaga non pemerintah dan swasta berperan dalam fasilitasi, pendampingan dan pembinaan.

Dampak yang diberikan oleh Kampung KB kepada masyarakat yakni kemudahan bagi ibu untuk menerima pelayanan kesehatan dan program KB, pelayanan kesehatan anak dan beberapa lainnya. Dilanjutkan, penambahan terhadap jumlah Kampung KB yang ada. Untuk lebih menyebar ke masyarakat. Dan masyarakat yang ada dapat masuk dalam keluarga sejahtera.

\section{Target dan sasaran Kampung KB}

Sejalan dengan tujan pembentukannya terdapat tiga fungsi utama rumah data kependudukan, yakni sebagai pusat intervensi permasalahan kependudukan, KB dan pembangunan keluarga, serta sebagai pusat integrasi aktivitas Kampung Kb. Rumah data kependudukan memang dalam konsep dasar difungsikan sebagai pusat data dan intervensi permasalahan kependudukan yang mencakup sistem pengelolaan dan pemenfaatan data kependudukan ditingkat mikro, mulai dari mengindentifikasi dan pemanfaatan data kependudukan yang bersumber dari, oleh dan untuk intervensi pembangunan di Kampung KB dalam upaya peningkatan kesejahteraan masyarakat. Merangsang kesadaran bina keluarga balita, untung merangsang tumbuh kembang anak.

\section{Program Kampung KB}

Membentuk keluarga kecil, dengan mempertimbangkan usia kawin dan pengaturan kelahiran, Keseimbangan antara pengeluaran dan pendapatan untuk menggali sumber ekonomi, dengan membuat program UPPKS (Usaha Peningkatan Pendapatan Keluarga Sejahtera), 8 Fungsi keluarga (fungsi agama, fungsi sosial budaya, fungsi cinta dan kasih sayang, fungsi perlindungan, fungsi reproduksi, fungsi sosialisasi dan pendidikan, fungsi ekonomi, fungsi lingkungan) dan membentuk POKTAN (Kelompok Kegiatan) perlu intervensi dari sektor terkait.

\section{METODE}

Penelitian ini menggunakan sumber data primer melalui survei wawancara langsung kepada responden meggunakan kuesioner untuk mendapatkan data-data terkait variabel yang diteliti. Data yang diperoleh dalam penelitian ini adalah data yang bersumber dari responden PUS yang ada di Kampung KB di Kecamatan Muara Bulian Kabupaten Batanghari sebanyak 216 responden PUS.

Untuk pengambilan sampel penelitian dilakukan dengan Pengambilan Sampel Acak Berdasar Area (Cluster Random Sampling). Peneliti Memilih Kecamatan Muara Bulian sebagai wilayah pengambilan sampel dengan menyebarkan kuesioner sebanyak 216 responden kriteria responden 15-49 tahun yang ada di Kecamatan Muara Bulian di 2 desa yang akan diteliti yg mengikuti program Kampung KB. Menetapkan 216 sampel tersebut dilihat dari beberapa wanita dengan usia 15-49 tahun yang sudah menikah dan jumlah PUS yang ada di 2 desa tesebut untuk dijadikan sampel dan diambil sebanyak 30 $\%$ dari jumlah PUS yang ada di 2 desa tersebut.

Analisis secara statistik deskriptif dilakukan untuk mengetahui gambaran profil Kampung KB di kecamatan muara bulian kabupaten batanghari. Deskriptif hasil 
penelitian dilakukan untuk mendeskripsikan sesuatu, seperti misalnya bagaimana karakteristik PUS yang ada di Kampung KB terhadap fertilitas.

Alat analisis yang digunakan adalah analisis regresi berganda, dengan Pengujian Hipotesis Secara Simultan (Uji-F) dan Pengujian Hipotesis Secara Parisal (Uji-t).

\section{HASIL DAN PEMBAHASAN}

\section{Profil Kampung KB di Kecamatan Muara Bulian Kabupaten Batanghari}

Hasil pengolahan data diketahui bahwa jumlah PUS yang ada di Kecamatan Muara Bulian Kabupaten Batanghari terdiri dari 2 desa yaitu desa sungai baung dan desa napal sisik. Berikut olahan datanya sejak 2015, 2018, 2020. Karena 3 tahun tersebut yang di data oleh BKKBN Kabupaten Batanghari. Didata oleh BKKBN 3 tahun sekali, tahun 2015 tahun pertama adanya program Kampung KB di Kacamatan Muara Bulian, tapi untuk tahun 2020 di ambil untuk tahun terkahir yang seharusnya tahun 2021.

Berdasarkan perbandingan data PUS dan kesertaan KB hasil dari tahun 2015, 2018, 2020 dari data BKKBN tahun 2020 sebagai berikut :

Tabel 1. Profil perbandingan Data PUS dan kesertaan KB hasil dari Tahun 2015, 2018, 2020 di Kampung KB di Kecamatan Muara Bulian Kabupaten Batanghari

\begin{tabular}{|c|c|c|}
\hline Tahun & Desa Napal Sisik & Desa Sei.Baung \\
\hline \multicolumn{3}{|l|}{2015} \\
\hline PUS & 146 & 502 \\
\hline PUS Ber-KB & 124 & 318 \\
\hline$\%$ PUS Ber-KB & 85 & 63 \\
\hline Jumlah Tenaga & 1 & 1 \\
\hline Medis & 1 & 1 \\
\hline \multicolumn{3}{|l|}{ Posyandu } \\
\hline \multicolumn{3}{|l|}{2018} \\
\hline PUS & 171 & 465 \\
\hline PUS Ber-KB & 148 & 335 \\
\hline$\%$ PUS Ber-KB & 87 & 72 \\
\hline Jumlah Tenaga Medis & 1 & 1 \\
\hline Posyandu & 1 & 2 \\
\hline \multicolumn{3}{|l|}{2020} \\
\hline PUS & 153 & 472 \\
\hline PUS Ber-KB & 140 & 354 \\
\hline$\%$ PUS Ber-KB & 92 & 75 \\
\hline Jumlah Tenaga Medis & 1 & 1 \\
\hline Posyandu & 1 & 2 \\
\hline
\end{tabular}

Sumber :Hasil olahan data BKKBN tahun 2020(diolah)

Dari Tabel.1 terlihat bahwa jumlah PUS di Kecamatan Muara Bulian Kabupaten Batanghari, berdasarkan data dari BKKBN bahwa di desa napal sisik yang ber-KB lebih banyak dibandingkan dari yang tidak ber-KB dilihat dari persennya 85 persen, begitu juga di tahun 2018 semakin meningkat sebanyak 87 persen, dan kemudian semakin meningkat lagi di tahun 2020 sebanyak 92 persen. Sedangkan di desa sungai baung yang ber-KB juga lebih banyak dibandingkan dari yang tidak ber-KB pada tahun 2015 sebanyak 63 pesen, dan ditahun 2018 sebanyak 72 pesen yang ber-KB dan pada tahun 2020 yang berKB meningkat sebanyak 75 persen. 
Dan terlihat bahwa di desa sungai baung dari tahun 2015 sampai sekarang sedikit meningkat persen nya di bandingkan desa napal sisik yang sangat banyak meningkatnya yang mengikuti KB. Hal ini mungkin disebabkan oleh wanita yang ada di desa sungai baung banyak yang tidak bekerja. Dibandingkan dengan desa napal sisik yang banyak bekerja bersawah berdagang dan berjualan sehingga berpengaruh pada tingkat fertilitas perempuan dan mengikuti program KB. Dan dilihat dari profil perbandingan Kampung KB dari sebelum ada Kampung KB dan setelah adanya Kampung KB sangat mengalami perbedaan. Dilihat dari tingkat fertilitasnya sangat berpengaruh dan wanita yang ada di Kampung KB sudah banyak mengikuti program KB dan jumlah anak yang dilahirkan dari 2015 sampai sekarang sangat sedikit.

\section{Deskripsi tingkat fertilitas di Kampung KB di Kecamatan Muara Bulian}

Hasil pengolahan data diketahui bahwa tingkat fertilitas di Kecamatan Muara Bulian di Desa Sei.Baung adalah sebanyak 295 jiwa dari 472 Pasangan Usia Subur (PUS) Selama Tahun 2015, 2016, 2017, 2018, 2019, 2020. Dan di Desa Napal Sisik adalah sebanyak 106 jiwa dari 153 Pasangan Usia Subur (PUS) selama Tahun 2015, 2016, 2017, 2018, 2019, 2020. Berdasakan data Tahun 2015, 2016, 2017, 2018, 2019, 2020 dikelompokkan sebagai berikut :

Tabel 2. Deskripsi tingkat fertilitas di Kampung KB Kecamatan Muara Bulian Kabupaten Batanghari

\begin{tabular}{ccc}
\hline Tahun & Desa napa sisik (jiwa) & Desa Sei.Baung (Jiwa) \\
\hline 2015 & 21 & 55 \\
2016 & 20 & 45 \\
2017 & 22 & 47 \\
2018 & 15 & 51 \\
2019 & 17 & 45 \\
2020 & 11 & 52 \\
\hline Rata-rata & 106 & 295 \\
\hline
\end{tabular}

Sumber :Hasil olahan data BKKBN tahun 2020(diolah)

Dari Tabel 2 terlihat tingkat fertilitas di desa napal sisik sangat menurun di bandingkan awal masuk Program Kampung KB di desa tersebut. Secara jumlah diawal tahun adanya Program Kampung KB pada tahu 2015 sejumlah 21 jiwa. Kemudian diikuti tahun berikutnya tahun 2016 berjumlah 20 jiwa, tahun 2017 sejumlah 22 jiwa, tahun 2018 sejumlah 15 jiwa, tahun 2019 sejumlah 17 jiwa dan tahun 2020 sejumlah 11 jiwa. Jika terlihat dari total nya tidak begitu banyak dan menurun tingkat fertilitas yang ada di Kampung KB di desa tersebut dibandingkan dengan jumlah PUS sebanyak 153 PUS. Dan di desa Sei.Baung juga sangat menurun di bandingkan awal masuk Program Kampung $\mathrm{Kb}$ di desa tersebut. Secara jumlah di awal tahum adanya Program Kampung KB di desa tersebut pada tahun 2015 sejumlah 55 jiwa, diikuti tahun berikutnya pada tahun 2016 sejumlah 45 jiwa, tahun 2017 sejumlah 47 jiwa tahun 2018 sejumlah 51 jiwa, tahun 2019 sejumlah 45 jiwa, tahun 2020 sejumlah 52 jiwa. Jika dilihat dari totalnya sedikit menurun tingkat fertilitas dari tiap tahun nya dan dilihat dari jumlah PUS nya yg sebanyak 472 PUS. itu artinya bahwa PUS yang mengikuti Program Kampung KB sudah berhasil dan mengikuti Program-program yang ada di Kampung KB tersebut untuk menurunkan 
tingkat fertilitas dan menurunkan jumlah angka kelahriran. Hal ini secara usia telah mengerti bahwa Usia Kawin Pertama harus di ats 20 tahun, secara pendapatan berpengaruh secara ekonomi untuk membatasi angka kelahiran. Secara pendidikan sangat bepengaruh untuk menunda kelahiran dan secara status pekerjaan juga sangat berpengaruh untuk jumlah kelahiran karena semakin wanita bekerja semakin membatasi jumlah fertilitas tersebut.

Analisis pengaruh tingkat usia kawin pertama, pendapatan keluarga, pendidikan, status pekerjaan terhadap Fertiltas di Kecamatan Muara Bulian Kabupaten Batanghari.

Setelah semua data kuesioner yang disebarkan kepada responden di Kampung KB di desa sungai baung dan desa napal sisik di Kecamatan Muara Bulian. Langkah kedua adalah proses mendeskripsikan dan menganalisis data. Dalam menyebarkan kuesioner kepada 216 responden, adapun hasil penelitian disajikan dalam benytuk deskripsi data, pengusian hipotesis dan pembahasan hasil penelitian. Analisis ini digunakan untuk menganalisis seberapa besar nilai tiap-tiap variabel independent yang mempengaruhi tingkat variabel dependent. Berikut ini adalah tabel yang dapat dijadikan acuan untuk mengetahui persamaan Regresi Linear Berganda pada penelitian ini :

Tabel 3. Hasil analisis

\begin{tabular}{rlrrrrr}
\multicolumn{7}{c}{ ANOVA $^{\mathbf{a}}$} \\
& Model & $\begin{array}{c}\text { Sum of } \\
\text { Squares }\end{array}$ & \multicolumn{1}{c}{ Df } & $\begin{array}{c}\text { Mean } \\
\text { Square }\end{array}$ & \multicolumn{1}{c}{ F } & \multicolumn{1}{c}{ Sig. } \\
\hline 1 & Regression & 128,866 & 5 & 25,773 & 65,119 & \multirow{2}{*}{$000^{\mathrm{b}}$} \\
& Residual & 83,116 & 210 &, 396 & & \\
& Total & 211,981 & 215 & & & \\
\hline
\end{tabular}

a. Dependent Variable: Y

b. Predictors: (Constant), X4, X3D1, X3D2, X2, X1

Sumber: Data diolah, 2021

Fertilitas yang berpendidikan SLTP lebih tinggi 0,155 dibandingkan dengan yang berpendidikan SD atau yang tidak sekolah. Tidak ada perbedaan fertilitas yang berpendidikan SLTA+ dengan mereka yang berpendidikan SD atau tidak sekolah. Tidak ada perbedaan fertilitas antara yang bekerja dengan yang tidak bekerja.

Tabel 4. Hasil coefficients

\begin{tabular}{|c|c|c|c|c|c|c|}
\hline & \multirow[t]{2}{*}{ Model } & \multicolumn{2}{|c|}{$\begin{array}{c}\text { Unstandardized } \\
\text { Coefficients }\end{array}$} & \multirow{2}{*}{$\begin{array}{c}\text { Standardized } \\
\text { Coefficients }\end{array}$} & \multirow[t]{2}{*}{$\mathbf{t}$} & \multirow[t]{2}{*}{ Sig. } \\
\hline & & B & Std. Error & & & \\
\hline \multirow[t]{6}{*}{1} & (Constant) & $-1,604$ &, 562 & & $-2,856$ & ,005 \\
\hline & $\mathrm{X} 1$ & ,113 & ,031 & ,232 & 3,631 & ,000 \\
\hline & $\mathrm{X} 2$ &, 734 & ,081 & ,537 & 9,087 &, 000 \\
\hline & X3D1 & , 195 &, 107 & ,093 & 1,828 & ,069 \\
\hline & X3D2 &,- 083 &, 115 &,- 036 &,- 722 & ,471 \\
\hline & $\mathrm{X} 4$ &, 152 &, 100 &, 076 & 1,518 &, 131 \\
\hline
\end{tabular}

a. Dependent Variable:

Sumber: Data diolah, 2021 


\section{Uji F dan uji t}

\section{Uji F}

Berdasarkan Tabel $F=65,119$ dari probabilita $0,000<\propto=0,1$. Bahwa Usia Kawin Pertama berpengaruh secara simultan. Dari probabilita $0,000<\propto=0,1$. Bahwa Pendapatan Keluarga berpengaruh secara simultan. Dari probabilita $0,069<\propto=0,1$. Bahwa berpendidikan SLTP berpengaruh secara simultan. Dari probabilita $0,471>\propto=$ 0,1 . Bahwa berpendidikan SLTA+ tidak berpengaruh secara simultan. Dari probabilita $0,131>\propto=0,1$. Bahwa Status pekerjaan tidak berpengaruh secara simultan.

\section{Uji t}

Uji ini diterapkan dengan membandingkan nilai probabilita t terhadap $\propto=0,1$. Dari probabilita $0,000<\propto=0,1$. Dengan demikian bahwa Usia Kawin Pertama berpengaruh secara simultan. Dengan membandingkan nilai probabilita t terhadap $\propto=0,1$. Dari probabilita $0,000<\propto=0,1$. Dengan demikian bahwa Pendapatan Keluarga berpengaruh secara simultan. Dengan membandingkan nilai probabilita t terhadap $\propto=0,1$. Dari probabilita $0,069<\propto=0,1$. Dengan demikian bahwa beprendidikan SLTP berpengaruh secara simultan. Dengan membandingkan nilai probabilita t terhadap $\propto=0,1$. Dari probabilita $0,471>\propto=0,1$. Dengan demikian bahwa berpendidikan SLTA+ tidak berpengaruh secara simultan. Dari probabilita $0,131>\propto=0,1$. Dengan demikian bahwa Status Pekerjaan tidak berpengaruh secara simultan.

\section{Koefisien determinasi}

Berikut ini adalah tabel yang bisa digunakan untuk mengetahui nilai koefisien determinasi dalam penelitian ini :

Tabel 5. Hasil determinasi

\begin{tabular}{lcrrrr}
\hline Model & R & R Square & $\begin{array}{c}\text { Adjusted R } \\
\text { Square }\end{array}$ & $\begin{array}{l}\text { Std. Error of } \\
\text { the Estimate }\end{array}$ & $\begin{array}{l}\text { Durbin- } \\
\text { Watson }\end{array}$ \\
\hline $1 \quad, 780^{\text {a }}$ &, 608 & \multicolumn{1}{c}{, 599} &, 62912 &, 579 \\
\hline a. Predictors: (Constant), X4, X3D1, X3D2, X2, X1 & & \\
b. Dependent Variable: Y & & & & \\
Sumber: Data diolah, 2021
\end{tabular}

Dari Tabel 5, nilai yang dijadikan acuan koefisien determinasi adalah nilai pada Adjusted R Square, yakni sebesar 0,599 (59,9\%). Artinya variabel independet (Usia Kawin Pertama, Pendapatan, Pendidikan SLTP, Pendidikan SLTA+, Status Pekerjaan) mempengaruhi variabel Fertilitas sebesar 59,9\%. Sedangkan sisanya 40,1\% dipengaruhi oleh variabel lain yang tidak diteliti dalam penelitian.

\section{Analisis pengaruh UKP terhadap fertilitas}

Variabel Usia Kawin Pertama memiliki nilai signifikansi $0,000<0,1$ sehingga menolak H0 yang berarti bahwa variabel Usia Kawin Pertama memberikan pengaruh yang signifikan terhadap fertilitas. Besarnya pengaruh ditunjukkan dengan nilai $\mathrm{B}=$ 0,113. Variabel Usia Kawin Perrtama dengan Nilai $B=0,113$. Oleh karena nilai B bernilai positif dengan kejadian UKP. Nilai koefisien Usia Kawin Pertama sebesar 0,113. 
Ini berarti jika variabel Usia Kawin Pertama naik sebesar satu satuan, akan menaikkan fertilitas sebesar 0,113 di atas 0,1 .

\section{Analisis pengaruh pendapatan keluarga terhadap fertilitas}

Variabel Pendapatan memiliki nilai signifikansi $0,000<0,1$ sehingga menolak $\mathrm{H} 0$ yang berarti bahwa variabel pendapatan memberikan pengaruh yang signifikan terhadap fertilitas. Besarnya pengaruh ditunjukkan dengan nilai $\mathrm{B}=0,734$. Ini berarti jika variabel pendapatan keluarga naik sebesar satu satuan, akan menaikkan fertilitas sebesar 0,734 di atas 0,1 .

\section{Analisis pengaruh pendidikan SLTP terhadap fertilitas}

Variabel Pendidikan SLTP memiliki nilai signifikansi 0,069>0,1 sehingga dapat dikatakan menerima $\mathrm{HO}$ atau variabel pendidikan SLTP tidak berpengaruh terhadap fertilitas atau variabel pendidikan SLTP tidak terbukti secara signifikan mempengaruhi fertilitas. Besarnya pengaruh ditunjukkan dengan nilai $\mathrm{B}=0,195$. Ini berarti jika variabel pendiidikan SLTP naik sebesar satu satuan, akan menaikkan fertilitas sebesar 0,195 di atas 0,1 .

\section{Analisis pengaruh pendidikan SLTA + terhadap fertilitas}

Variabel Pendidikan SLTA+ memiliki nilai signifikansi 0,471>0,1 sehingga dapat dikatakan menerima $\mathrm{H} 0$ atau variabel pendidikan SLTA+ tidak berpengaruh terhadap fertilitas atau variabel pendidikan SLTA+ tidak terbukti secara signifikan mempengaruhi fertilitas. Besarnya pengaruh ditunjukkan dengan nilai $\mathrm{B}=-0,083$. Ini berarti jika variabel pendiidikan SLTA+ naik sebesar satu satuan, akan menaikkan fertilitas sebesar - 0,083 di atas 0,1 .

\section{Analisis pengaruh status pekerjaan terhadap fertilitas}

Variabel Status Pekerjaan memiliki nilai signifikansi 0,131>0,1 sehingga dapat dikatakan menerima H0 atau variabel Status Pekerjaan tidak berpengaruh terhadap fertilitas atau variabel status pekerjaan tidak terbukti secara signifikan mempengaruhi fertilitas. Besarnya pengaruh ditunjukkan dengan nilai $\mathrm{B}=0,152$. Ini berarti jika variabel pendiidikan SLTA+ naik sebesar satu satuan, akan menaikkan fertilitas sebesar 0,152 di atas 0,1 .

\section{KESIMPULAN DAN SARAN}

\section{Kesimpulan}

Hasil pengolahan data perbandingan profil Kampung KB di Kecamatan Muara Bulian diketahui bahwa jumlah PUS yang ada di Kecamatan Muara Bulian Kabupaten Batanghari bahwa di desa sungai baung dari tahun 2015 sampai sekarang sedikit meningkat persen nya di bandingkan desa napal sisik yang sangat banyak meningkatnya yang mengikuti KB. Hal ini mungkin disebabkan oleh wanita yang ada di desa sungai baung banyak yang tidak bekerja. Dibandingkan dengan desa napal sisik yang banyak bekerja bersawah berdagang dan berjualan sehingga berpengaruh pada tingkat fertilitas perempuan dan mengikuti program KB. Dan dilihat dari profil perbandingan Kampung KB dari sebelum ada Kampung KB dan setelah adanya Kampung KB sangat mengalami perbedaan. Dilihat dari tingkat fertilitasnya sangat berpengaruh dan wanita yang ada di 
Kampung KB sudah banyak mengikuti program KB dan jumlah anak yang dilahirkan dari 2015 sampai sekarang sangat sedikit. Bahwa PUS yang mengikuti Program Kampung KB sudah berhasil dan mengikuti Program-program yang ada di Kampung KB tersebut untuk menurunkan tingkat fertilitas dan menurunkan jumlah angka kelahriran. Hal ini secara usia telah mengerti bahwa Usia Kawin Pertama harus di atas 20 tahun, secara pendapatan berpengaruh secara ekonomi untuk membatasi angka kelahiran. Secara pendidikan sangat bepengaruh untuk menunda kelahiran dan secara status pekerjaan juga sangat berpengaruh untuk jumlah kelahiran karena semakin wanita bekerja semakin membatasi jumlah fertilitas tersebut. Dan dari variabel-variabel tersebut mempunyai peluang untuk menambah fertilitas lebih dari 2.

\section{Saran}

Untuk masyarakat baik PUS maupun remaja di Kampung KB di desa napal sisik dan desa sei.baung hendaknya lebih ditingkatkan. Agar terwujudnya keluarga yang sejahtera, untuk pemerintah, menurut data Kampung KB yang ada di Kecamatan Muara Bulian Kabupaten Batanghari. Desa Napal Sisik dan Desa Sei.Baung sangat paling rendah di tingkat Kecamatan Muara Bulian Kabupaten Batanghari. Dengan demikian perlu perhatian lebih terhadap peningkatan partisipasi dalam program pengenalan Program KB melalui pelatihan dan penyuluhan tentang pentingnya Program dalam Kampung $\mathrm{Kb}$ terutama dalam pasangan yang baru menikah. Penyuluhan tersebut dilaksanakan agar pengetahuan dan kesadaran masyarakat meningkat karena faktor yang mengikutsertakan masyarakat desa napal sisik dan desa sei.baung dalam Program KB, untuk Pemerintah Daerah setempat agar memberikan alat kontrsepsi secara gratis agar masyarakat di 2 desa tersebut dengan lebih meudah mendapatkannya.

\section{DAFTAR PUSTAKA}

Adioetomo, Sri Moertingsih., \& Samosir, Omas Bulan. (2010). Dasar-dasar demografi. edisi 2. Salemba Empat: Jakarta

Apriyanti, Darsono, Trisnaningsih. (2014). Hubungan tingkat pendidikan dan nilai anak dengan fertilitas pasangan perkawinan usia muda. Tesis. Pascasarjana Pendidikan IPS Fakultas Keguruan dan Ilmu Pendidikan Universitas Lampung: Lampung

Arum Wahyungingsih. (2016). Kajian karakteristik Kampung keluarga (KB) di Desa Mojoranu Kecamatan Sooko Kabupaten Mojokerto. Kajian Karakteristik Kampung KB di Desa Mojoranu Kecamatan Sooko Kabupaten Mojokerto, 1(1), $1-8$

Badan Pusat Statistik. (2020). Batang Hari Dalam Angka. Kabupaten Batanghari

Badan Pusat Statistik. (2021). Proyeksi jumlah pertumbuhan penduduk Tahun 20102020. Provinsi Jambi: Jambi

BKKBN. (2020). Jumlah fertiltas dan pasangan usia subur. Kabupaten Batanghari.

BKKBN.(2020). Daftar nama Kecamatan dan Kelurahan Kampung KB Kabupaten Batanghari. Kabupaten Batanghari.

Brown,P. (1984a). Recripocal teaching of comprehension-fostering and comprehensionmonitoring activities. Center for the study of reading University of Illinois. Tanggal 12 Februari 2016, Pukul 10.00 WIB. 
Enderu Setia Adi. (2013). Faktor yang mempengaruhi fertilitas di Desa Kandangteous Kecamatan Senduro Kabupaten Lemajang. Skripsi. Fakultas Ekonomi Universitas Jember: Jawa Timur

Gaffar, Fahri Muhammad. (1994). Pendidikan dan pengentasan kemiskinan. Majalah Pendidikan: Bandung.

H Hardiani, D Hastuti, I Islakhiyah, J Junaidi. (2020). Determinants of Long-Acting and Permanent Methods (LAPMS) of contraception use in Jambi Province, Indonesia, Jurnal Perspektif Pembiayaan dan Pembangunan Daerah, 8(4), 353-368

Hatmadji. (2004). Dasar-dasar Demografi. Fakultas Ekonomi Universitas Indonesia: Jakarta

Hidayatul Ainy, Siti Nurrchmah, Septa Katmawanti. (2018). Hubungan antara fertilitas, mortalitas, dan migrasi dengan laju pertumbuhan penduduk. Preventia: The Indonesian Journal of Public Health, 4(1), 1-8

Irawan, Prasetya. (2006). Penelitian kualitatif dan kuantitatif untuk ilmu-ilmu sosial. Departemen Ilmu Administrasi FISIP UI: Depok

Lawson, David W.; Mace, Ruth. (2010).Optimizing modern family size trade-offs between fertility and the economic costs of reproduction. Hum Nat 21(2010), 3961.

Lucas, David dkk. (1990). Pengatar Kependudukan, cetakan keempat. Gaddjah Mada Uiversity Press: Yogyakarta

Mantra IB. (2004). Demografi umum. Pustaka Pelajar. Yogyakarta.

Mantra Ida Bagus. (2003). Pengantar studi demografi. Nur Cahaya.

Mantra, SC. (2000). Demografi umum. Pustaka Pelajar: Yogyakarta

Mardiyono. (2017). Kampung KB Sebagai upaya pemberdayaan masyarakat/keluarga di Jawa Timur. Jurnal Cakrawala 11(2), 129 - 136

Munir (1984). Makalah Pengelolaan Tanah. Diakses dalam online]:http:// adibfauzanh0712004.blogspot.com/2014/, Tanggal 4 Jauli 2018, Pukul 12.00 WIB

Purwanti. (2003). Analisis faktor-faktor sosial ekonomi yang mempengaruhi fertilitas di Kecamatan Plokaro Sukoarjo. Other thesis, Universitas Sebelas Maret.

Rahmadewi, Leli Asih. (2011). Tingkat Fertilitas Di Nusa Tenggara Timur dan Yogyakarta. Kesmas, Jurnal Kesehatan Masyarakat Nasional, 6(3), 117-125

Sri Yuniarti, Tri Setiowati. (2015). Analisis faktor yang berhubungan dengan tingkat fertilitas pada ibu pasangan usia subur (PUS) di wilayah kerja puskesmas melong asih kota cimahi. Industrial Research Workshop and National Seminar, 6(2015), 176-183

Sugiyono. (2011). Metode penelitian kuntitatif kualitatif dan R\&D. Alfabeta: Bandung

Sugiyono. (2014). Metode Penelitian Pendidikan Pendekatan Kuantitatif, Kualitatif, dan R\&D. Bandung: Alfabeta.

Suharyadi dan Purwanto.( 2011). Statistika untuk ekonomi dan keuangan modern Edisi 2. Salemba Empat: Jakarta

Sulistyawati, A. (2013). Pelayanan keluarga berencana. Salemba Medika: Jakarta

Todaro, Michael. (2004). Pembangunan ekonomi di dunia ketiga. Edisi Kedelapan Erlangga: Jakarta

Tournemaine, F., \& Luangaram, P. (2012). R\&D, human capital, fertility, and growth. Journal of Population Economics,25(3), 923-953. 
Trihendradi,Cornelius. (2005). Statistik inferen teori dasar dan aplikasinya SPSS 12. Andi: Yogyakarta.

Yoni Malinda. (2010). Hubungan umur kawin pertama dan penggunaan kontrasepsi dengan fertiitas remaja bestatus kawin. Jurnal Kesehatan Reproduksi, 3(2), 69-81

Zulwida Rahmayeni. (2014). Faktor-faktor yang mempengaruhi fertilitas pasangan usia subur peserta KB di Kelurahan Aur Kuning Kecamatan Aur Birugo Tiga Baleh Bukit Tinggi. Jurnal Geografi, 8(2), 136-145 